\title{
Failure analysis of External load switch equipped in electricity meter
}

\author{
Yang Fuli, Hou Xingzhe, Zheng Ke \\ State Grid of Chonging Electric Power CO. Electric Power Research Institute, Chongqing 401123, \\ China \\ hcyfuli@163.com
}

Keywords: External load switch equipped in electricity meter; Mechanical operation; overload protection; Phase failure

\begin{abstract}
External load switch equipped in electricity meter play an important role in the normal operation of the terminal circuit and equipment. Therefore, it has important practical significance to analyze and improve the common failure modes of external load switch equipped in electricity meter. This paper introduces several common failure modes of external load switch equipped in electricity meter, analyzes the failure modes and takes the corresponding improvement measures, which can effectively improve the reliability of the use of external load switch equipped in electricity meter.
\end{abstract}

\section{Introduction}

The implementation of the standard GB 10963.1-2005 《Electrical accessories - Circuit breakers for overcurrent protection for household and similar installation-Prat 1: Circuit breakers for a.c. oparation》 external load switch equipped in electricity meter is one of the most commonly used low-voltage electrical products. It is widely used in the end of the line, used for overload and short circuit protection of electrical wiring and equipment in household and similar places, to protect the circuit and equipment from being damaged by the thermal and electrical power effect of fault current. Similarly, when the mis-operation caused by non- fault current occurs in external load switch, will bring great inconvenience or economic loss to the user. Therefore, it is necessary to analyze and improve the common failure modes of external load switch in order to improve the reliability of the protection capability of the external load switch.

\section{Operating principle and failure mode of External load switch equipped in electricity meter}

An external load switch is composed of operating mechanism, thermal release system, electromagnetic tripping system and contact system. Thermal release system connects in series with electromagnetic tripping system in protected circuit. The operating principle as shown in fig.1.When the operating mechanism close and the contact in a state of connection, The overload current is generated in the circuit or equipment and the double metal sheet is bent and deformed in the product. The bending deformation rate is related to the current value and the power on time. When the deformation is large enough to trigger release components, The operating mechanism to complete the trip and contact system disconnect; When circuit or equipment produce short circuit current, larger electromagnetic force is formed through the coil, when the short circuit current is large enough, the effect of electromagnetic force to overcome spring reaction force and will touch release components instantaneously. Making mechanical operation complete the trip and contact system disconnect. According to the national standard of GB10963.1, the time current operating characteristic of external load switch should meet the requirements of Table I . 


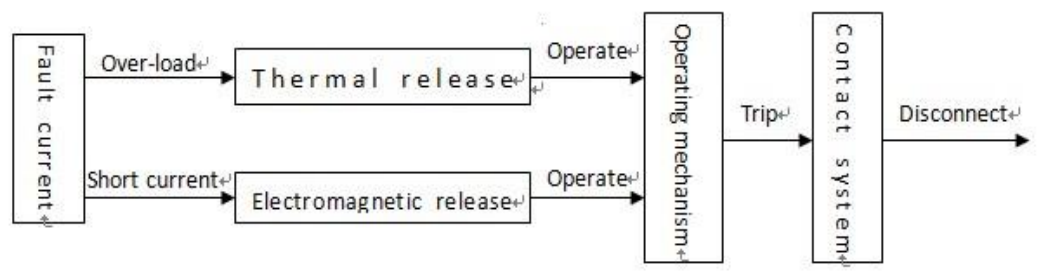

fig. 1 Operating principle of Miniature circuit breaker

In the process of operation of miniature circuit breaker products, the main failure modes are the three followings:

1) The mechanical operation fault: The operating mechanism cannot close to drive the contact system in closing state normally;

2) Unsteady thermal release system: Compared to the setting condition, Working condition of Thermal release element changed, which caused the circuit breaker refuse to operate when overload current is generated in a circuit or device or the wrong action occurs when the current is not expected;

3) Phase failure: Dynamic and static contact of contact system cannot connect properly, which result circuit or equipment in Phase failure and the electrical equipment to be unable to work normally or burning.

Table I Time-current operating characteristic

\begin{tabular}{|c|c|c|c|c|c|}
\hline Test & Type & Test current & Initial condition & $\begin{array}{l}\text { Limits of tripping or non-tripping } \\
\text { time }\end{array}$ & $\begin{array}{l}\text { Results to be } \\
\text { obtained }\end{array}$ \\
\hline $\mathrm{a}$ & B、 C、D & $1.13 \mathrm{In}$ & Cold & $\begin{array}{l}\mathrm{t} \leqslant 1 \mathrm{~h}(\operatorname{In} \leqslant 63 \mathrm{~A}) \\
\mathrm{t} \leqslant 2 \mathrm{~h}(\operatorname{In}>63 \mathrm{~A})\end{array}$ & No tripping \\
\hline $\mathrm{b}$ & B、C、D & $1.45 \mathrm{In}$ & $\begin{array}{l}\text { Immediately } \\
\text { following test a }\end{array}$ & $\begin{array}{l}\mathrm{t}<1 \mathrm{~h}(\operatorname{In} \leqslant 63 \mathrm{~A}) \\
\mathrm{t}<2 \mathrm{~h}(\operatorname{In}>63 \mathrm{~A})\end{array}$ & Tripping \\
\hline $\mathrm{C}$ & $B 、 C 、 D$ & $2.55 \mathrm{In}$ & Cold & $\begin{array}{c}1 \mathrm{~s}<\mathrm{t}<60 \mathrm{~s} \quad(\operatorname{In} \leqslant 32 \mathrm{~A}) \\
1 \mathrm{~s}<\mathrm{t}<120 \mathrm{~s} \quad(\operatorname{In}>32 \mathrm{~A})\end{array}$ & Tripping \\
\hline $\mathrm{d}$ & $\begin{array}{l}\text { B } \\
C \\
D\end{array}$ & $\begin{array}{c}3 \mathrm{In} \\
5 \mathrm{In} \\
10 \mathrm{In}\end{array}$ & Cold & $\mathrm{t} \leqslant 0.1 \mathrm{~s}$ & No tripping \\
\hline $\mathrm{e}$ & $\begin{array}{l}\text { B } \\
\text { C } \\
\text { D }\end{array}$ & $\begin{array}{l}5 \text { In } \\
10 \text { In } \\
20 \text { In }\end{array}$ & Cold & $\mathrm{t}<0.1 \mathrm{~s}$ & Tripping \\
\hline
\end{tabular}

\section{Failure analysis and improvement of External load switch equipped in electricity meter}

\subsection{Failure analysis and improvement of mechanical operation failure}

Most of mechanical operation of existing external load switch adopts four connecting rods or five connecting rods mechanism. In order to ensure that mechanism can also realize closing and tripping functions simultaneously, required by two connecting rods to engage and the two connecting rods called for a lock catch and a jump button. In the process of meshing and separation, the meshing surface is gradually worn out, after thousands of running in, the wear of the meshing surface can be reached $(0.2 \sim 0.3) \mathrm{mm}$ and in the part of the meshing surface appears "the collapse surface". At this point, in the process of closing, the lock catch lose locking function and unable to bear the connecting rod of operation mechanism into a state of "dead zone", so the circuit breaker cannot close normally.

Through the analysis, two kinds of improvement measures can be taken in view of the above 
failure phenomena: one is to improve lock materials and enhance the wear-resisting property of the materials. The other is to improve lock structure design, add the mesh margin of lock catch and jump button. Considering the improvement of wear resistant material is not easy to process and will greatly increase the cost of materials. Therefore, we adopt the second improvement scheme: Adding mesh margin of the lock catch and jump button, while improving supporting strength of the meshing surface of lock catch.

By using simulation software ADAMS 2013 to carry on the simulation analysis, see fig. 2 and formulated the improvement plan. Before and after improvement, the lock structure as shown in fig. 3 . Through the improvement, the mechanical operation life times are significantly improved, and the comparison of the mechanical operation life of the before and after improvement see Table II .
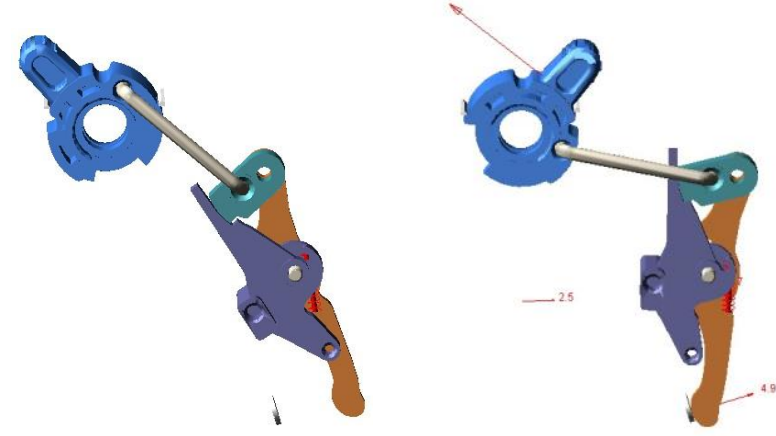

fig. 2 ADAMS 2013 simulation analysis
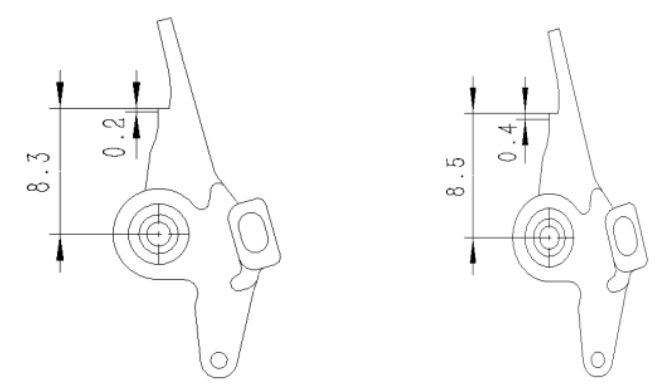

(a) before improvement (b) after improvement

fig.3 Lock structure

Table II The comparison table of the mechanical life of lock structure before and after the

\begin{tabular}{ccccccc}
\multicolumn{1}{c}{ improvement } \\
\hline Test item & \multicolumn{1}{c}{ Before improvement } & \multicolumn{3}{c}{ After improvement } \\
Mechanical & $1 \#$ & $2 \#$ & $3 \#$ & $1 \#$ & $2 \#$ & $3 \#$ \\
operation (times) & 4560 & 5210 & 4780 & 6605 & 6530 & 6550 \\
\hline
\end{tabular}

\subsection{Analysis and improvement of unstable thermal release system}

Thermal release system instability is mainly manifested in the circuit breakers: it refuses to operate when overload current is generated in a circuit or device, or the wrong action occurs when the overload current does not achieve expected value. As a core component of thermal release system, Thermal bimetal element influences the stability of thermal release system of circuit breaker significantly. There are two main factors affecting the stability of thermal release system:

1) Under the current $1.13 \mathrm{In}$ and $1.45 \mathrm{In}$, the temperature change of the thermal metal element is not obvious, which makes the bending deformation variable less and the sensitivity low.

2) The heat and moisture deformation of the shell and other plastic parts and the change of the 
position of the bimetallic element caused by the vibration of the product during transportation, which make the circuit breaker overload protection characteristic curve drift. In the process of verification and analysis, we measured the temperature of the dual metal element in the $1.13 \mathrm{In}$ current at $110{ }^{\circ} \mathrm{C}$ $\sim 130 \mathrm{C}^{\circ} \mathrm{C}$ and the temperature in $1.45 \mathrm{In}$ current at $150^{\circ} \mathrm{C} \sim 175^{\circ} \mathrm{C}$. At this time, the thermal bimetal element work in the linear temperature range, and the temperature difference is relatively large with good sensitivity. At the same time, the setting position of the bimetallic metal is measured again, it is found that compare to the complete set of miniature circuit breakers, after storage and handling of external load switch, the whole set position of the bimetallic metal has obvious fluctuations, and the amount of volatility reached $(0.3 \sim 0.5) \mathrm{mm}$.

In view of the failure caused by the change of the position of the bimetallic element, We have taken the addition of a tower shaped pressure spring between the adjusting end of the bimetallic element and the casing. As shown in fig.4. Bimetallic element can maintain a relatively stable working position and can reduce the influence of the heat of the shell, the deformation of moisture and the vibration of transportation between the control end of the bimetallic metal element and the outer shell in the common role of adjusting screw and tower shaped pressure spring.

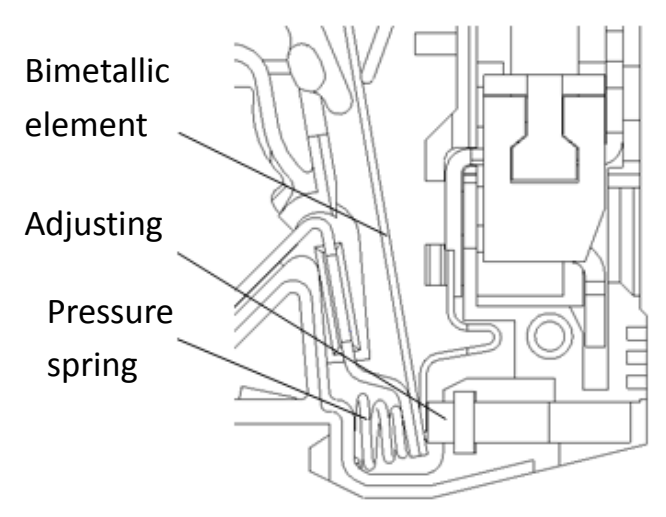

fig.4 Thermal release system

\subsection{Analysis and improvement of phase failure}

The phase failure of external load switch is the disappearance of the over travel between the dynamic and static contacts, the dynamic and static contact cannot be reliably contacted when the handle is closed. After analysis, it is found that the reason for this kind of situation is that the melting and deformation of contact surface and change of material composition under the action of electric arc and contact Joule heat, which damage the normal operation of the contact and reduce the contact reliability of contact .Reliability reduction of contact increased the internal temperature of the product. The dynamic contact and the plastic support are deformed under the action of internal high temperature, and the over travel between the dynamic contact and static contacts becomes smaller and smaller until it disappears.

In view of the above failure, we have adopted the Ansys software simulation to analysis, as shown in fig.5. According to the analysis, designed to improve contact structure and to increase the margin of the over travel. Reducing the influence of the deformation of the contact support on the over travel and improving the reliability of the contact between the contacts. Before and after the improvement of the dynamic contact structure as shown in fig.6.

In order to verify the improvement effect, we have arranged each three samples before and after the improvement to through rated current for 168 hours at the enclosed environment with the 
temperature of 75 degree Celsius and the humidity of $90 \% \mathrm{RH}$. The comparison is shown in Table III, in which $1 \# \sim 3 \#$ are the samples before improvement, and $4 \# \sim 6 \#$ are the samples after improvement. As can be seen from the table, the change after the improvement is significantly smaller than before, the improvement program has achieved the desired effect.

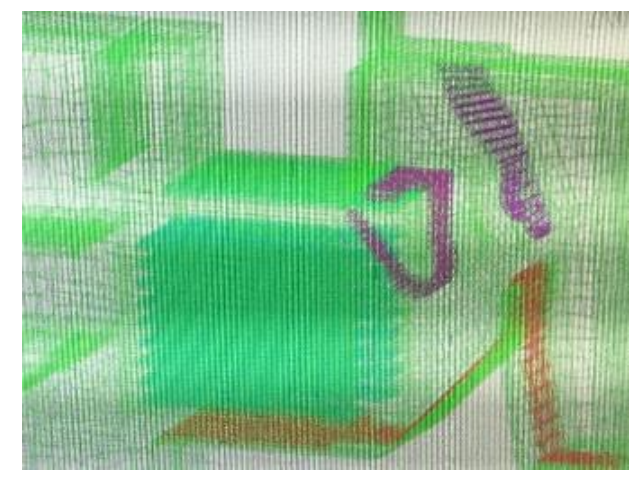

fig.5 Ansys simulation analysis
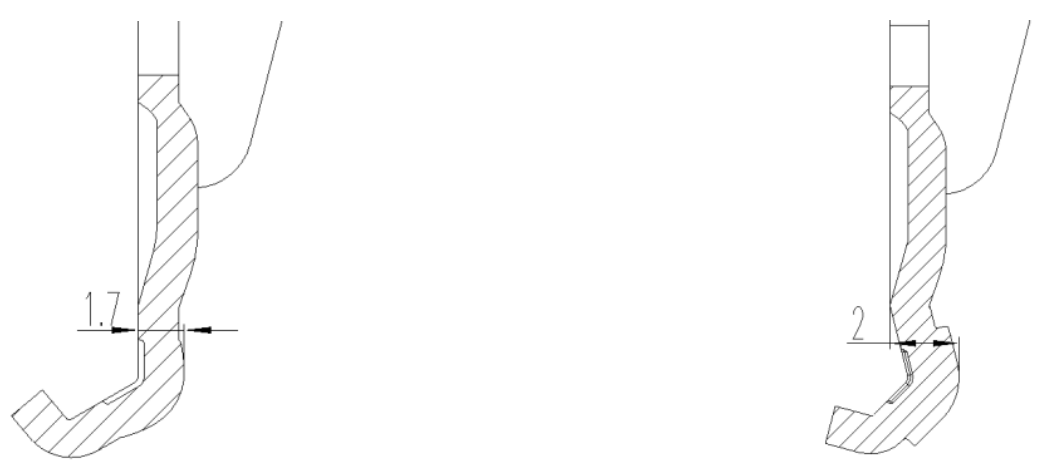

(a) dynamic contacts before improvement

(b) dynamic contacts after improvement

fig.6 dynamic contact structure

Table III The comparison table of the over travel of before and after the improvement the dynamic contacts

\begin{tabular}{ccccccc}
\hline $\begin{array}{c}\text { Sample No } \\
\text { over travel }\end{array}$ & $1 \#$ & $2 \#$ & $3 \#$ & $4 \#$ & $5 \#$ & $6 \#$ \\
$\begin{array}{c}\text { before test } \\
(\mathrm{mm})\end{array}$ & 1.2 & 1.35 & 1.25 & 1.55 & 1.6 & 1.50 \\
$\begin{array}{c}\text { over travel } \\
\text { after test }\end{array}$ & 0.5 & 0.45 & 0.55 & 1.1 & 1.05 & 1.05 \\
$\quad(\mathrm{~mm})$ & & & & & & \\
variation & -0.7 & -0.9 & -0.7 & -0.4 & -0.45 & -0.45 \\
\hline
\end{tabular}

\section{Conclusion}

Through analyzing the common failure modes of external load switch, it takes the measures to add the mesh margin of lock catch and jump button. It takes the tower shaped pressure spring to design to stabilize the position of the bimetallic element and improve dynamic contact design structure.so that ,the operation life of mechanical product has been improved, the overload protection characteristics is more stable, phase failure rate has been reduced, the reliability of the product has been improved in the process of using. 


\section{Acknowledgment}

This work is supported by State Grid Corporation of science and technology project :(Support electricity meter fee charged with load switch testing and reliability evaluation technology research), all support is gratefully acknowledged.

\section{Reference}

[1] GB 10963.1 《Circuit-breakers for overcurrent protection for household and similar installation -Part 1: Circuit-breakers for a.c. operation》

[2] GB 10963.2 《Circuit-breakers for overcurrent protection for household and similar installation -Part 2: Circuit breakers for a.c. and d.c. operation》

[3] GB 14048.2 《Low-voltage switchgear and controlgear-Part 2: Circuit breakers》

[4] Chen Degui 《The arc and current limiting technology of the low-voltage circuit breaker》[M]. Beijing: Mechanical Industry Press, 2006.

[5] Lu Jianguo. 《Test and detection of low-voltage electrical device》[M]. Beijing: Electric Power Press, 2007.

Author introduction:

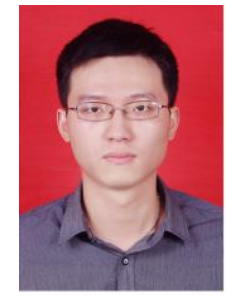

Yang Fuli (1987-), male, Graduate student, Engaged in the miniature circuit breaker, load switch, watt-hour meter, transformer, etc。Email: hcyfuli@163.com

Hou Xingzhe (1965-), male, Graduate student, Senior Engineer, Engaged in electric energy measurement, electric energy meter research and other related work。

Zheng Ke (1975-), Graduate student, Senior Engineer, Engaged in electric energy measurement, electric energy meter research and other related work。 